\title{
Stability of bioactive compounds and antioxidant activities of kenaf seed oil-in-water nanoemulsions under different storage temperatures
}

\begin{abstract}
Kenaf seed oil-in-water nanoemulsions (NANO) stabilized by sodium caseinate (SC), betacyclodextrin ( $\beta$-CD), and Tween 20 (T20) have been optimized and shown to improve in vitro bioaccessibility and physicochemical stability in the previous study. The main objective of this study was to evaluate the stability of bioactive compounds and antioxidants in the NANO during storage at different temperatures $\left(4{ }^{\circ} \mathrm{C}, 25{ }^{\circ} \mathrm{C}\right.$, and $\left.40{ }^{\circ} \mathrm{C}\right)$. An evaluation of the antioxidant activities of each emulsifier showed that $\mathrm{SC}$ had good scavenging capability with 97.6\% ABTS radical scavenging activity. Therefore, SC which was used as one of the main emulsifiers could further enhanced the antioxidant activity of NANO. At week 8 of storage, NANO that stored at $4{ }^{\circ} \mathrm{C}$ had maintained the best bioactive compounds stability and antioxidant activities with $90 \%$ retention of vitamin $\mathrm{E}$ and $65 \%$ retention of phytosterols. These results suggested that $4{ }^{\circ} \mathrm{C}$ would be the most suitable storage temperature for NANO containing naturally present vitamin $\mathrm{E}$ and phytosterols. From the accelerated storage results at $40{ }^{\circ} \mathrm{C}$, NANO containing vitamin $\mathrm{E}$ and phytosterols had maintained half of its initial concentration until week 4 and week 2 of storage, which is equivalent to 16 weeks and 8 weeks of storage at room temperature, respectively.
\end{abstract}

Keyword: Antioxidants; Nanoemulsions; Phytosterols; Scavenging activity; Vitamin E 